\begin{tabular}{|c|c|c|c|c|c|}
\hline RA (India) & $=3.117$ & SIS (USA) & $=0.912$ & ICV (Poland) & $=6.630$ \\
\hline SI (Dubai & 0.829 & РИНЦ (Russia) & $=0.156$ & PIF (India) & $=1.940$ \\
\hline IF (Australia) & $=0.56$ & ESJI (KZ) & $=8.716$ & IBI (India) & $=4.260$ \\
\hline $\mathbf{F}$ & $=1.500$ & SJIF (Morocco) & $=5.667$ & ОАJI (USA) & $=0.350$ \\
\hline
\end{tabular}

Impact Factor:

SOI: $\underline{1.1 / \mathrm{TAS}}$ DOI: $\underline{10.15863 / \mathrm{TAS}}$

International Scientific Journal Theoretical \& Applied Science

p-ISSN: 2308-4944 (print) e-ISSN: 2409-0085 (online)

Year: 2019 Issue: 02 Volume: 70

Published: 17.02.2019 http://T-Science.org

SECTION 12. Geology. Anthropology.

Archaeology.
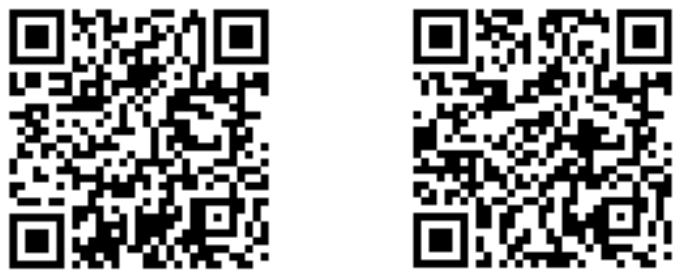

Elnur Latif oglu Hasanov Corresponding member of International Academy of Theoretical and Applied Sciences, Ph.D., Institute of Local lore of Ganja Branch Azerbaijan National Academy of Sciences, Ganja, Azerbaijan el-hasanov@mail.ru

\title{
ABOUT INNOVATIVE INVESTIGATION OF NATIONAL-MORAL VALUES OF GANJA BASED ON MATERIAL SAMPLES AND LOCAL TRADITIONS
}

Abstract: Main historical and religious monuments of the ancient city Ganja were explored as important sources of studying traditional tolerant values. It also revealed important arguments about the typical characteristics of the preservation of multiculturalism among the population of this city for centuries based on various historical sources, archival materials and scientific literatures. In this academic paper have been explored some of the characteristic features of the centuries-old craftsmanship and architectural styles of the city, were investigated the problems of application of these styles in the main religious and architectural monuments, that have survived to the present day too.

Key words: Azerbaijan, Ganja, handicraft samples, multidisciplinary research, innovative methods, ethnographic research.

Language: Russian

Citation: Hasanov, E. L. (2019). About innovative investigation of national-moral values of Ganja based on material samples and local traditions. ISJ Theoretical \& Applied Science, 02 (70), 154-159.

Soi: http://s-o-i.org/1.1/TAS-02-70-12 Doi: croskef https://dx.doi.org/10.15863/TAS.2019.02.70.12

\section{ОБ ИССЛЕДОВАНИИ НАЦИОНАЛЬНО-ДУХОВНЫХ ЦЕННОСТЕЙ ГЯНДЖИ НА ОСНОВЕ МАТЕРИАЛЬНЫХ ОБРАЗЦОВ И МЕСТНЫХ ТРАДИЦИЙ}

Аннотация: Основные историко-религиозные памятники древнего города Гянджи были исследованы как важные источники изучения традиционных толерантных иченностей. Также были выявлены важные аргументы о характерных особенностях сохранения мультикультурализма среди населения этого города в течение веков на основе разных исторических источников, архивных материалов и научных литератур. В данной научной статье также были изучены некоторые характерные особенности многовековых ремесленных и архитектурных стилей города, исследован вопрос о внедрении данных стилей в основных религиозно-архитектурных памятниках, сохранившихся до наших дней.

Ключевые слова: Азербайджан, Гянджа, ремесленные образиы, междисичилинарные исследования, инновационные методы, этнографические исследования.

\section{Introduction}

Гянджа, один из древнейших городов Востока с многовековой историей, соединяющий северо-восточные склоны гор Малого Кавказа (древних Гянджинских гор) с просторами КураАракской низменности, расположен в живописном уголке Азербайджана с умеренным климатом, плодородными землями, богатыми водными ресурсами.
Исторически Гянджа всегда имела выгодное геополитическое расположение и играла важную роль в культурной и экономической жизни Азербайджана. Этот город был построен на Великом Шелковом Пути, который соединяет Азию с Европой. Таким образом, Гянджа являлся духовным мостом между разными цивилизациями.

Античный философ Страбон (I век до нашей 


\begin{tabular}{|c|c|c|c|c|c|c|}
\hline \multirow{4}{*}{ Impact Factor: } & ISRA (India) & $=3.117$ & SIS (USA) & $=0.912$ & ICV (Poland) & $=6.630$ \\
\hline & ISI (Dubai, UAE & $=0.829$ & РИНЦ (Russia & $=0.156$ & PIF (India) & $=1.940$ \\
\hline & GIF (Australia) & $=0.564$ & ESJI (KZ) & $=8.716$ & IBI (India) & $=4.260$ \\
\hline & JIF & $=1.500$ & SJIF (Morocco & $=5.667$ & OAJI (USA) & $=0.350$ \\
\hline
\end{tabular}

эры) отмечал о древней Гяндже:

«Здесь один раз посаженная почва дает урожай два или даже три раза в год. Орошение почвы лучше, чем в Вавилоне и Египте. Кроме этого, здесь воздух особенно чист и целебен» [6].

Говоря о Гяндже автор XIV века, историк Хамдуллах Газвини писал:

Есть всего несколько избранных городов,

Настоящий клад в Арране - Гянджа.

Полна изобилия, вода чиста,

Климат мягок и просторны долины [2].

По вопросу этимологии названия города ученые предлагали разные варианты, но пришли к единому мнению, что свое название Гянджа берет от древних тюркских племен «Генджек»ов.

Важно иметь ввиду факт о том, что название Гянджи упоминалось в таких древних источниках как «Шахристане Иран» и др.

На основе неоспоримых археологических и этнографических материалов было доказано существование поселений на территориях древней Гянджи еще в эпоху Неолита, то есть VII-VI тысячелетий до нашей эры.

Первые археологические раскопки в долине реки Гянджачай проводились в конце XIX века со стороны Дюбуа де Манпере, Ф. Баерна, Э. Реслера, Я. Гуммеля и других зарубежных ученых-археологов. Позднее историкоархеологические поисковые работы были проведены Азербайджанскими археологами и впервые месторасположение города Гянджи было полно и всесторонне изображено И. Джафарзаде [5].

\section{Materials and Methods}

Благодаря многовековым национальноморальным ценностям этот город считался своеобразным «индикатором» социальнокультурного и политико-общественного строя в течение многих веков. Так как, именно Гянджа был основным центром основных исторических реформ, важных национальных восстаний против вражеских войск, наступавших на нашу родину.

В 1231 году именно в Гяндже - на родине великого мыслителя и поэта Ренессанского периода Востока Низами Гянджеви (1141-1209), первой женщины философа, шахматистки и композитора Мехсети Гянджеви (1096-1160) ремесленник-гончар Бендер возглавил национально-освободительное движение против монголов и Харезмшахов.

В 1804 году великий полководец, последний правитель Гянджинского Хантсва Джавад хан вместе с сыновьями срожался до последнего за родину, сдержав свое обещание, что захватнические царские войска смогут войти в Гянджу только после его смерти $[6 ; 8]$.
Один из самых древних православных церкоей в Западном регионе страны находится в Гяндже и до сих пор здесь верующие выполняют свои религиозные обряды, отмечают важные исторические даты, праздники. А этот древний храм охраняется как важный историкоархитектурный памятник и жители города с уважением относятся к православным верующим. Один из самых крупных и в тоже время древних немецких лютеранских храмов тоже сохранился в нашем древнем городе и объявлен историкоархитектурным памятником. Несмотря на то, что основная часть верующего населения города мусульмани, но в городе жители в течение веков с особым уважением охраняли древние албанские христианские храмы, а также грузинскую церковь и другие памятники.

Как географические названия и топонимы, так и фольклор, сохранившийся до современных времён, олицетворяют в себе богатое культурное наследие азербайджанских тюрков (азербайджанцев), изначально живущих на этой территории. Местные жители занимались здесь ремесленничеством, земледелием и животноводством. Фольклор, мифы и легенды, сказки, поэтические примеры как плод богатого воображения местных жителей также являются показателями мировоззрения поселившихся здесь людей. Кроме мифов и повествований, отражающих традиционное тюркское миропонимание, в этом регионе создавались также рассказы, увековечившие в себе маленькую историю каждого географического названия и священного места. Обнаруженные в древних жилых постройках и отражавшие огромную культурную историю бытовые вещи и драгоценности, а также орудия могут расцениваться как жемчужины искусства. Эти образцы вместе с отражением общих эстетических взглядов жителей, показывают также богатство и многосторонность традиционного мастерства.

Обладающие красочной и богатой природой, Гянджа и окрестные районы, в основном, считаются нагорными и предгорными регионами. Многоводные реки, луга сделали эту территорию пригодной особенно для животноводства. Климатическая полоса придаёт особый цвет и оттенок этому региону. Если Самухский, Горанбойский и Шямкирский районы отличаются богатыми садами, виноградниками и субтропическими растениями, то Гядябяй и Дашкясян больше всего славятся альпийскими лугами и горными растениями. Помимо богатых лесных покровов с деревьями дуба, граба, груши, яблони, черешни, ореха, кизила и алычи, в степях произрастает полынь, красочные растения, а на скалах разные кустарники. Многосторонность и сложность рельефа сделала неповторимым и его 


\begin{tabular}{|c|c|c|c|c|c|c|}
\hline \multirow{4}{*}{ Impact Factor: } & ISRA (India) & $=3.117$ & SIS (USA) & $=0.912$ & ICV (Poland) & $=6.630$ \\
\hline & ISI (Dubai, UAE & $=0.829$ & РИНЦ (Russia) & $=0.156$ & PIF (India) & $=1.940$ \\
\hline & GIF (Australia) & $=0.564$ & ESJI (KZ) & $=8.716$ & IBI (India) & $=4.260$ \\
\hline & JIF & $=1.500$ & SJIF (Morocco) & $=5.667$ & OAJI (USA) & $=0.350$ \\
\hline
\end{tabular}

растительный мир. Словно ковёр этот регион переливается яркими и красочными цветами высоких гор и альпийских лугов. Эти факторы обуславливают получение качественной шерсти, а также природных красок, обеспечив развитие животноводства, в частности овцеводства [3].

В Гяндже вполне развито ковроткачество. Традиционные виды тканей, предусмотренные иногда для разного вида одеяний, ткались в определенном количестве. В таком случае вид одежды отождествлялся с названием ткани. Сюда можно отнести и джеджимы. Созданные по технике тканья джеджимов «йорганузу», «дёшекузу», “джанамаз», «юк пардаси», «тахса пардаси», «мутакка узу» определяли как название ткани, так и вид изделия.

Во многих деревнях региона Гянджи ткалась и бязь. В этом смысле славятся жители Самуха. Помимо того, что они ткали превосходные ковры, шёлковые и полушёлковые ткани, но также производили и высококачественную хлопковую ткань изысканно белого цвета, называя её «лжаламая». Из самой тонкой нити хлопка производилась марля, а из её двойного или втрое скрученного вида - джаламая (тонко белое). Джаламая - это вид плотно сотканной хлопковой ткани, которая производилась в Гяндже. В возникновении производства шерстяных изделий в Азербайджане, помимо разновидности сырьевых запасов (овечья, верблюжья, козлиная шерсть и др.), решающую роль сыграло изобилие растений.

В конце XIX века в Азербайджане по наличию шерстяных запасов важное место занимала Гянджа и окрестные районы. В исторических источниках есть известие о том, что в этом регионе имеется сто тысяч овец, что сообщает и о количестве шерстяного запаса на тот период. Это изобилие допускало создание разных видов шерстяных изделий. Основным занятием гянджинских девушек тогда было тканые ковров и ковровых изделий. Основываясь на факты 1841 года, связанные с Гянджой, можно сказать, что в каждой деревне женщины ткали ковры, килимы, черпаки, мешки, портпледы и очень тонкие, высококачественные шали, которые назывались «махуд». Длина каждой шали составляла до 7 аршинов (0,71 м), ширина 4 четверти (1/4 аршина или 17,75 см). В зависимости от качества каждая шаль по рыночным ценам того времени стояла от 7 манат до 10 серебряных монет. В XIX веке в Азербайджане одним из центров художественной вышивки была Гянджа. Здесь широко распространились виды «гязма» и «долдурма» вышивки текалдуз (тамбурная вышивка). Живущие на этой территории зажиточные семьи предпочитали покрывать верхнюю част своих юрт белым войлоком. По этой причине они заказывали обрасти - войлоки из белой шерсти.

\section{Applied significance of research}

Гянджа один из немногих городов, где существовали такие жилые кварталы как «Улица евреев», «Лезгинский квартал», «Квартал лагич (лахыдж)» и др., где представители других наций жыли в мире и покое.

Гянджа столица первой демократической республики мусульманского Востока и в XX веке сохранила свой статус центра национальногосударственных ценностей. В Гяндже 1918 году были приняты более 200 государственных документов, постанавлений и решений о провозглашении родного языка, о создании национальной армии, о подтверждении флага государства и др.

Гянджинцы гордые, но гуманные, простые люди. Против зла они боролись до конца, но всегда защищали слабых, нуждающихся в помоще людей. Сегодня эти духовные ценности сохраняются и соблюдаются, как и много тысячелетий назад.

Гянджинцы за сохранение государственности, укрепление стратегии всестороннего развития страны, за целостность родины, освобождение оккупированных территорий и соблюдение стабильности в стране. Наш город всегда являлся и сегодня сохраняет статус важного культурно-научного и промышленного центра, городом с многовековыми толерантными ценностями [4].

В быту жителей региона Гянджи важное место занимают ковры и ковровые изделия. Здесь ткались молельные коврики намазлыг, черпаки, килимы и другие текстильные изделия. Богатая природа края придала коврам этого региона особые оттенки, одарила яркими окрасами цветовое разрешение композиции ковров. Разноцветные краски - главные особенности, отличающие ковры этого региона от других. В узорно - композиционном выбора ковров особое место придавалось воображению, мифическим взглядам, вере местных жителей. Всё это нашло своё отражение на коврах. Мифические птицы, животные, а также семантически наполненные элементы, зависящие от миропонимания, были специфичными для ковров этого региона. Можно сказать, что ковры Гянджи, в которых ощущаются тесные отношения с разными группами ковроткачества Азербайджана, выступают как главные категории сознания и чувств живущих на этой территории людей.

Основными производственными пунктами ковров Гянджинской группы являются Гянджа и окрестные сёла, а также районы Гядябяй, Горанбой, Шямлир, Дашкясян и Самух. Естественно, что сотканные в каждом из этих 


\begin{tabular}{|c|c|c|c|c|c|c|}
\hline \multirow{4}{*}{ Impact Factor: } & ISRA (India) & $=3.117$ & SIS (USA) & $=0.912$ & ICV (Poland) & $=6.630$ \\
\hline & ISI (Dubai, UAE & $=0.829$ & РИНЦ (Russia & $=0.156$ & PIF (India) & $=1.940$ \\
\hline & GIF (Australia) & $=0.564$ & ESJI (KZ) & $=8.716$ & IBI (India) & $=4.260$ \\
\hline & JIF & $=1.500$ & SJIF (Morocco & $=5.667$ & OAJI (USA) & $=0.350$ \\
\hline
\end{tabular}

пуктов ковры отличаются своеобразными формами. В общем, характерными для гянджинских ковров особенностями являются их длина, высокий ворс, разная плотность петель и относительное крупные размеры. Безворсовые ковры тоже характеризуются разной плотностью. В этом регионе пользовались не столь уж крупными переносными маленькими станками, которые были удобны в домах и дворах при плетении ковров, а для боде больших ковров брались крупные стационарные станки. Процесс ткания основы на этих клетках осуществлялся трудом нескольких профессиональных мастеров.

В Гяндже - центре древнего ковроткачества - помимо ковроткачества, распространилось войлочное мастерство, т.е. изготовление войлоков, который используется в скотоводстве. Особенно в предгорных областях этого региона приготовленные войлоки были очень полезными для покрытия верхней и окружной части хижин, а также при покрытии тележек во время кочевья.

Войлоки обычно изготовливались из белой и чёрной шерсти. Хижины, также в зависимости от покрывающих их войлока, назывались «аг дая» (белая хижина) и «гара дая» (чёрная хижина). Безусловно, что палатки, помимо войлоков, украшались ворсовыми и безворсовыми коврами. Среди безворсовых ковров своей красотой выделялись паласы, джеджимы и килимы.

В Гянджинском региона, где развито шелководство, сотканные шёлковые джеджимы на станках нашли своё применение в каждой семье со своими яркими цветовыми оттенками, изящными узорами, тонкими тканями.

Сотканные вручную как ворсовые, так и безворсовые ковры (хурджун, мафраш (портплед), мешок, сумка для соли, мутакка (продолговатая подушечка) с ковровым покрытием и другие текстильные изделия) служили приданными для девочек.

Техническое влияние гянджинских ковров можно наблюдать также на коврах Газаха и Гарабаха.

Ворс ковров сотканных в Гяндже, обычно быль более длинным и густым. Потому что помимо эстетического значения, ковёр предусматривался для удержания теплоты комнаты в холодную погоду.

У гянджинских ковров имеется также своеобразное индивидуальное колоритное разрешение. Так, на привлекательных своими цветами коврах Гянджи больше всего наблюдаются яркие оттенки. Наиболее используемые цвета - это голубой, зелёный, желтый, черный и сахарный тона.

Гянджинская группа больше всего известна композициями «Гянджа», «Гядим Гянджа», «Гядябяй», «Чыраглы», «Самух», «Фахралы».
Сотканные здесь образцы ковров «Самух», «Чайлы», «Фахралы» обладают стабильной формой закрытого типа, художественным построением с озёрами промежуточного участка.

Основной производственный центр отличающегося художественным построением ковра «Гядим Гянджа» расположен на северо западе Шямкирского района и окрестностях Гянджи. Этот ковёр обладает специфическим художественным построением. Промежуточный участок даётся с полосами, украшенными последовательно или в диагональной форме, и внутри них бывают слетка нанизанные элементы «бута». Эти узоры от элементов «бута» на коврах Баку, Ширвана, Гарабаха и Сараба отличаются индивидуальным художественным построением и цветовым разрешением. В народе этот ковёр известен такими наименованиями, как «Гядим халча», «Гянджа бута», «Буталы Гянджа». Ковер «Хантирма», созданный в Гарабахе под влиянием ковров Гянджи, напоминает ковёр «Гяадим Гянджа». С развитием торговых отношений Гянджи можно предположить, что образец «Гядим Гянджа» появился под влиянием дизайнерской оформленности тканей тирма, завезённых сюда с Востока еще в далёком прошлом.

Один из ковров Гянджинской группы связан с названием деревни Фахралы округа Борчалы. Эти ковры были самыми известными, обладали индивидуальным художественным построением. Как правило, эти ковры ткались небольшими по размеру и предназначались для совершения намаза (мусульманской молитвы). Верхняя част ковра окружена контурами арки, внутри промежуточного участка изображено озеро в геометрической форме. Изображение арки еще раз подтверждает предназначенность ковра. Поэтому в народе эти ковры называются «джанамаз» [5; 6].

Узоры ковров Гянджи, в основном, состоят из украшающих элементов в геометрической форме. У каждого узора имеется свой смысл и назначение. Именно по этой причине ковры использовались в разных ритуалах: при сватовстве девушек, траурных и похоронных обрядах, во время обетов, при совершении намаза, во время гадания, рождении ребенка и др. Предусмотрев эти символы, можно догадываться о древности этих узоров. На основе вышеуказанного можно предположить, что в древние времена ковры были не в каждом доме. Ковёр был в употреблении ограниченного количества людей, по своим узорам и по их значениям в подходящих моментах превращался в украшения дворцов и подарки царей. Впоследствии распространился среди народа, и превратился в товар. На поверхности сотканных ковров в Гяндже вплеталась дата его 


\begin{tabular}{|c|c|c|c|c|c|c|}
\hline \multirow{4}{*}{ Impact Factor: } & ISRA (India) & $=3.117$ & SIS (USA) & $=0.912$ & ICV (Poland) & $=6.630$ \\
\hline & ISI (Dubai, UAE & $=0.829$ & РИНЦ (Russia & $=0.156$ & PIF (India) & $=1.940$ \\
\hline & GIF (Australia) & $=0.564$ & ESJI (KZ) & $=8.716$ & IBI (India) & $=4.260$ \\
\hline & JIF & $=1.500$ & SJIF (Morocco & $=5.667$ & OAJI (USA) & $=0.350$ \\
\hline
\end{tabular}

производства по хиджре, имя мастера и даже условные знаки извещающие принадлежность.

Больше всего на коврах Гянджи ткачами использовались изображения озёр со ступенчатыми краями, узоры с крючком, ромбом, крестообразные элементы, треугольник, восьмиугольная звезда, джейран, птица, тавро. Узоры набати или изображения фантастических животных наносились, в основном, мелкими, поэтому не играли важной роли на коврах. Эти узоры передают многовековую историю. Аналог этих стилей изображения не имеется у других народов. Они сочетаются с наскальными изображениями, находящиеся на территории Азербайджана, и мотивами на фаянсовых посудах. Значение узоров, сотканных на гянджинских коврах, не изучалось, до сегодняшнего дня, а возможно, что их смысл невозможно будет раскрыть вовсе. Но некоторые из них можно объяснить. Это виды узоров исходящие от верований. Восьмиугольная звезда возникла из веры в небесные существа, ромб толкуется как женское начало мира, плодородие, символ изобилия, крестообразный мотив олицетворяет четыре элемента, четыре полюса, создающие мир, ступенчатые озёра - это символ возвышенного пути, ведущий к богу, треугольник тоже путь, ведущий на небеса и к богу [16].

Комплекс Имамзаде, расположенный на территории Государственного историкокультурного заповедника одного из древних центров науки и культуры - города Гянджи, был воздвигнут в 739 году над могилой Мовлана Ибрагима - сына пятого имама Мухаммед Багира, правнука Гусейна ибн Али - внука пророка Мухаммеда. Этот памятник является одним из основных символов города.

Слово «Имамзаде» происходит от понятия «дитя имама» и означает «потомок рода имамов». В народе название Имамзаде считается священным местом поклонения и паломничества.

Многие члены «Ахли-бейта», бежавшие от преследований и гонений в период правления династии Омейядов (661-750), нашли пристанище на окраинах халифата. Хазрат Ибрагим (а) переселился в один из центров исламской культуры - город Гянджу. Хазрат Ибрагим (а) до конца жизни прожил на этой земле, где и был похоронен. Над могилой Мовлана Ибрагима был возведен мавзолей (тюрбе), а сама гробница стала священным местом паломничества [1].

Территория мавзолея, построенного в VIII веке, была расширена в XIV-XVI веках, а постройки вокруг него были воздвигнуты в основном в XVII-XVIII веках. Мавзолей - это самый ценный исторический памятник комплекса Имамзаде. Высота его составляет 12 м, высота купола - 2.7 м, диаметр равен 4.4 м. Снаружи купол покрыт голубой облицовкой [2].
В XX веке на внутренних стенах гробницы был обнаружен значимый историкоэпиграфический образец - древнее писание, которое было исследовано видными иисследователями - археологом, профессором Исагом Джафарзаде, а также видным ученым в области эпиграфики, членом Национальной академии наук Азербайджана Мешадиханум Нейматовой, и читалось следующим образом:

«Он, Аллах, вечен. Это сыну имама Мухаммеда Багира Мовлана Ибрагима (благословение ему) славный (райский) сад. Он скончался спустя 120 лет после своего деда, - да благословит его Аллах!»

В результате научного исследования этого исторического писания стало известно, что мавзолей сыну Имама был воздвигнут в 739 г.

Территория места паломничества Имамзаде входила во владения представителей рода великого азербайджанского поэта и мыслителя Низами Гяджеви - Шейхзамановых. На протяжении веков гробница Мовлана Ибрагима свято оберегалась и была местом поклонения. По указанию легендарного полководца, последнего хана Гянджи Джавадхана Зиядоглу (1748-1804 гг.), вписавшего свое имя в героическую историю Азербайджана, в Имамзаде были проведены широкомасштабные реставрационные работы.

В 1878-1879 годах по инициативе генералмайора Исрафил бека Ядигярзаде, а в начале XX века - гянджинской интеллигенции в комплексе Имамзаде был проведен капитальный ремонт [7].

В этом святом месте похоронены представители известных родов Шейхзамановых, Пишнамаззаде, Мирзы Мехди Наджи, представитель рода сеидов Мир Аббас Ага, генерал-майор Исрафил бек Ядигярзаде и другие видные личности. На протяжении веков Гянджинский комплекс Имамзаде был очагом благотворительности, оказывающим бескорыстную помощь нуждающимся и беззащитным.

В период с 1930 по 1944 год постройки комплекса были приспособлены под детский дом. Этот священный уголок приютил пострадавших во время войны малолетних детей разных национальностей. И сегодня приверженцы разных религиозных верований с чувством благодарности приезжают сюда, чтобы отдать дань почтения этому святому месту [5].

\section{Conclusion}

В Азербайджанской Республике толерантность и мультикультурализм имеют глубокие исторические корни и являются образом жизни народа. Сохранение различных религиозных, культурных и исторических памятников - один из основных приоритетов 


\begin{tabular}{|c|c|c|c|c|c|c|}
\hline \multirow{4}{*}{ Impact Factor: } & ISRA (India) & $=3.117$ & SIS (USA) & $=0.912$ & ICV (Poland) & $=6.630$ \\
\hline & ISI (Dubai, UAE & $=0.829$ & РИНЦ (Russia & $=0.156$ & PIF (India) & $=1.940$ \\
\hline & GIF (Australia) & $=0.564$ & ESJI (KZ) & $=8.716$ & IBI (India) & $=4.260$ \\
\hline & JIF & $=1.500$ & SJIF (Morocco & $=5.667$ & OAJI (USA) & $=0.350$ \\
\hline
\end{tabular}

государственной политики, заложенной общенациональным лидером азербайджанского народа Гейдаром Алиевым.

Многочисленные указы и распоряжения Президента Азербайджанской Республики Ильхама Алиева, преемника мудрой политики великого лидера Гейдара Алиева, по восстановлению и реставрации религиозных и историко-архитектурных памятников, а также проекты, претворяемые в жизнь под руководством президента Фонда Гейдара Алиева, посла доброй воли UNESCO и ISESCO Мехрибан Алиевой, являются ярким примером заботы нашего государства о богатом национально культурном наследии Азербайджана.

На основе семи указов, подписанных главой государства Ильхамом Алиевым в 2010-2015 гг., комплекс Имамзаде в городе Гяндже был заново реконструирован, на высоком уровне проведены строительные работы в традиционном гянджинском архитектурном стиле. В главном святилище воздвигнуты 2 минарета высотой 40 метров, построены отдельные молельные залы для мужчин и женщин. В комплексе построены помещения для гостей на 90 мест и комнаты для намаза.

Обновленный величественный комплекс Имамзаде - одно из священных мест исламского мира, жемчужина святынь Востока, и сегодня является местом паломничества не только местного населения, но и многочисленных паломников из зарубежных стран.

\section{References:}

1. Ohmədov, F. M. (2007). Gancənin tarix yaddaşı. Gəncə: Elm.

2. (2007). Azorbaycan etnoqrafiyast. 3 cilddə, I cild. (p.544). Bakı: Şərq-Qərb.

3. Mustafayev, C. M. (1998). Orta əsrlərdə sənətkar təşkilatları. Cahan jurnalı, № 4, 17- 21.

4. Guliyeva, N. M., \& Häsänov, E. L. (2014). Die traditionelle Gändschänischen Teppiche von Zeitraum der Aserbaidschanischen Gelehrten und Dichter Mirsä Schäfi Waseh als ethnoanthropologische quelle (XIX Jahrhundert). European Applied Sciences, 2, 3-5.

5. (1974). The dawn of Art. (p.196). Leningrad: Aurora Art Publishers.

6. Həmidova, İ. (2000). Azərbaycan parça sənətinin tarixi inkişaf yollart. Elmi axtarışlar, VIII toplu, Bakı.

7. Həsənov, E. L. (2015). Gəncə Imamzadə türbəsi anənəvi multikulturalizm abidəsi kimi. Qafqazda mədəni-dini irsin qorunması mövzusunda beynəlxalq konfransin materiallar1. (pp.117-120). Bak1.

8. Hovilov, H. A. (1991). Azarbaycan etnoqrafiyası. Bak1: Elm.

9. (n.d.). Azərbaycan Respublikası Milli Arxiv İdarəsi Dövlət Arxivinin Gəncə şəhər filialı. F. 20, s. 4, iş 11 .
10. Hasanov, S. L., \& Hasanov, E. L. (2018). Applied features of comparative technical, sociological investigation of historical and contemporary heritage of Azerbaijan. International Scientific Journal Theoretical \& Applied Science, Philadelphia (USA), Issue 1, vol. 57, part 1, 9-16.

11. Mustafayev, A. N. (2001). Azorbaycanda sanotkarliq. (p.232). Bak1: Altay.

12. Həsənov, E. L. (2012). Gəncə Imamzadə türbasi (tarixi-etnoqrafik tadqiqat). 1-ci nəşr. (p.268). Bakı: Elm və təhsil.

13. Ofkərov, Q. (1978). Gəncə şəhərinin məhəllə adlar1. Elm va hayat jurnalı, № 10, Bak1, 27.

14. Hasanov, E. L. (2018). Applied significance of investigation of handicrafts branches in Ganja city based on innovative technologies (Historical-ethnographic research). (p.110). Prague: Vědecko vydavatelské centrum «Sociosféra-CZ».

15. Chelkowski, P. (2008). Nizami Gandjawi, jamal al-Din Abu Muhammad Ilyas b. Yusuf b. Zaki Muayyad. Encyclopaedia of Islam. Edited by: P. Bearman, Th. Bianquis, C.E. Bosworth, E. van Donzel and W.P. Heinrichs (Eds.). Brill.

16. Nemət, M. S. (1992). Azərbaycanda pirlor. (p.104). Bakı: Azərnəşr. 